\title{
Developing a Strategy to Improve Reliability in Supply Chains
}

\author{
Irina V. Terenina ${ }^{1, *}$ Dmitry D. Kostoglodov ${ }^{2}$ Inga O. Protsenko ${ }^{3}$
}

\author{
${ }^{1}$ Don State Technical University, Rostov-on-Don, Russia \\ ${ }^{2}$ Rostov State Economic University, Rostov-on-Don, Russia \\ ${ }^{3}$ The Russian Presidential Academy of National Economy and Public Administration, Moscow, Russia \\ *Corresponding author. Email: teririn@yandex.ru
}

\begin{abstract}
The current stage in the evolution of logistics theory and supply chain management is characterized by an increasing interest in a range of new concepts, such as sustainable development, sustainability, strength, flexibility, adaptability, reaction speed, and reliability. The improvement of reliability and efficient organization of supply chains have an impact not only on the activities of individual economic entities included in this supply chain, but also on the pace and proportions of economic development of the Russian national economy as a whole.The article analyses domestic and foreign scientific works, which consider issues of supply chain reliability, essence and concept of strategic approach and strategic alternatives for optimal strategy formation of supply chain reliability improvement. Factors affecting the formation of reliability strategies in supply chains, requirements and methods ensuring reliability of supply chains are systematized. An integral indicator for evaluating the reliability of the supply chain is proposed and a system of reliability indicators is formulated. This indicator measures the quality of the developed strategy for improving the reliability of the supply chain and compares the reliability of the supply chain before and after the formation of the strategy and the reliability of the various supply chains.
\end{abstract}

Keywords: logistics, supply chain, reliability, evaluation methods, strategy, strategic horizons, strategic

alternatives

\section{INTRODUCTION}

The emerging market relations in the domestic economic space stimulate the possibility of moving away from traditional enterprise management, make it inevitable and economically feasible to switch from management in general sense to management and marketing suggesting the creation of a system of effective management decisionmaking algorithms taking into account changing market conditions.

Russia is among the countries with a high level oflogistics costs, which significantly reduces the efficiency of production and trade, negatively affects the competitiveness of companies and the country as a whole. In 2018, according to Russian experts, the share of logistics costs in the gross domestic product of the Russian Federation in reached $19 \%$, while in China it is $18 \%$, in Brazil and India - 11-13\%, in the USA - $8.5 \%$, in Italy $9.7 \%$, in Japan and Germany - $8.5 \%$ and $8.8 \%$, respectively. The average world logistics cost in 2017 is estimated by Armstrong \&AssociatesInc at $11.7 \%$.

Developing a supply chain reliability strategy is becoming increasingly important for both large and small and medium- sized enterprises. Enterprise participation in the supply chain is a critical factor in maintaining and improving income and competitiveness in current and future markets.

The term "supply chain management" was first proposed by the consulting firm Arthur Andersen in the early 1980s. The advent of SCM control concept is attributed to the publication of K. Oliver and M. Weber[13], in which the authors defined control of indivisible SCMs as a material flow going through distribution channels from supplier to buyer.

There are currently many definitions of the term "supply chain management," but it is generally accepted that "Supply chain management is the integration of key logistics processes starting from the end-user and covering all intermediaries and suppliers of goods, services and information that add value to consumers and other stakeholders." Common properties of SCM [15,18]are: safety, persistence, damage, stability, reliability, robustness, flexibility.

Supply chains are a complex multi-structure adaptive system with active elements operating in a dynamic market environment [19,20].

Supply chains during evolution and operation demonstrate reactivity, i.e. the ability to target adaptable behavior in complex environments, adequately to changes in both internal and external conditions. [16].

The theory of development of strategic and operational partnership has been considered in the works of many 
scientists such as JTMentzer, SMin, ZGZacharia, AOtto, HKotzab[1,2,4,5,12].Considering the theory of vertical partnership within supply chains, the authors do not highlight the industry features that are characteristic of the functioning of those or other economic entities in a given sphere of national economy.

The increasing competition in the logistics services market, the increasing complexity of logistics systems, and the increasing demands for maintaining a given level of logistics services have increased the interest and practical importance of research in improving the reliability of supply chains[17].

Bockarev A.A., Gregory M.N. Dolgov A.P. Uvarov

S.A[4,5,6,7]named the following as the most important tasks of study and improvement of supply chains:

- Improvement of the basic conceptual apparatus;

- Development and justification of criteria and indicators of reliability of supply chains and their elements taking into account technical, organizationaltechnological, economic, social and environmental factors;

- Development of a supply chain model;

- Development of models and methods for reliability analysis of supply chains;

- Development of recommendations to ensure the specified requirements for supply chain reliability.

The operation of supply chains is subject to considerable uncertainty. The sources of uncertainty can be demand fluctuations, forecast errors, resource failures, data inaccuracies, erroneous decisions of managers, inaccurate transmission of information and interpretation of certain events, targeted actions to destroy the supply chain (terrorism, theft of goods), as well as extreme cases such as changes in political or natural conditions.

At the same time, in a number of works $[6,9,10,21]$ there is a more detailed approach to evaluation of reliability of supply chains, suggesting investigation of chains in more detail, dividing them into a sequence of the simplest events possible. The most complex part of the work is the generation of a logic diagram of the sequence and mutual operations into which the circuit is broken

\section{OBJECT (PURPOSE)}

The purpose of improving the reliability of supply chains is to meet the needs of consumers as quickly and qualitatively as possible. It is the efficient operation of supply chains that can ensure that the necessary resources are delivered at the right time, place and quantity.

\section{THEORETICAL, INFORMATIONAL, EMPIRICAL, AND METHODOLOGICAL GROUNDS OF THE RESEARCH}

The need for a specific theoretical apparatus and practical tools for supply chain management depends on a number of factors that determine the level of development of productive forces, technologies, political situation, and maturity of market relations established at a certain historical stage. The possibility and pace of development of logistics approaches in domestic business should be considered in close connection with socio-economic, political factors affecting the economy of the Russian Federation.

The fundamental difficulties encountered in the development of the logistics concept in Russia can be formulated as follows:

1) High level of monopolism and state ownership in the most important sectors of the economy and social tensions in many segments of society. These factors hinder the promotion of logistics technologies for the development of domestic business.

2) Traditionally, for a long time in the domestic economy the role of the sphere of circulation (supply and marketing of products), which in the West occupies a key position in logistics, has been underestimated. Historically, in our country, the development of the circulation sphere has lagged far behind the production sphere, especially in the organization of the sale of goods and services. The sphere of circulation was characterized by slow promotion of goods from producers to consumers, high level of unmet demand, low reliability and insufficient quality of service to consumers.

3) Russia today is far behind even the average world level in the development of the infrastructure of the economy. There are some negative points such as

- Unsustainable development of distribution structures (lack of a well-thought-out strategy for the development of industrial and trade distribution systems, lack of organized commodity markets at large and medium wholesale levels);

- Weak level of development of modern electronic communication systems, electronic networks, communication systems and telecommunications;

- Weak transport infrastructure, especially in the area of roads; insufficient number and low technological level of road freight and multimodal terminals;

- The absence of modern vehicles in almost all modes of transport; High degree of physical and moral wear of rolling stock of transport;

- Low level of development of the production and technical base of the warehouse; Lack of modern technological equipment for cargo processing of products;

- Weak development of modern packaging industry, etc.

It was used such methods of a research as the dialectic and analytical methods, methods of justification of trends of development of chains of deliveries, a method of dynamic ranks, methods based on application of theorems of probability theory, function of algebra of logic, methods of search of hypotheses and others in work.

A strategy is like the path, which an organization chooses to move from the current state to the target state on the strategic horizon (fig.1). 


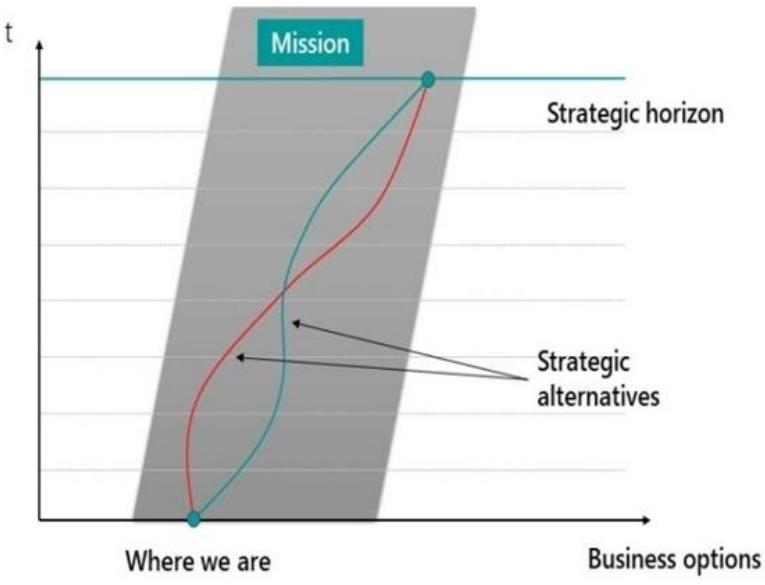

Figure 1 Strategic alternative in strategic targeting system

The mission of the organization (enterprise) is its main purpose, the raison d 'être of its existence. Mission is one of the fundamental concepts of strategic management.

Michael Meskon, Michael Albert, Franklin Hedoury [11] defined mission as the primary common purpose of an organization in which the reason for its existence is clearly expressed. The objectives of the organization are chosen to carry out this mission"

Konosuke Matsushita is a Japanese businessman, founder of Matsushita Electric, defined his organization's mission as fighting society's poverty and improving its well-being [8].

The expanded definition of mission discloses aspects such as:

1. purpose of the organizationfunctioning,

2. sphere of the organizationactivity,

3. philosophy of the organization,

4. Methods of achieving the objectives

5. Methods of interaction of the organization with society (social policy of the organization).

By strategic horizon, in this case, we will understand the period that the organization considers appropriate to use to set goals and develop a strategy.

The strategic objective is a system of basic guidelines for long-term development of the enterprise, according to which a corporate strategy is developed and a policy on the main aspects of activity is formed: increase of income; growth of sales volumes; increase in a share of the market; creation and improvement of the image, fame of the enterprise and its products, etc.

The strategic alternative is possible options for moving from the current state to the target state on the strategic horizon.

\section{RESULTS}

The strategy for improving the reliability of supply chains (fig. 2)in terms of the system approachis to develop a mechanism that balances the amount of uncertainty space with that of the system..

The development of such a strategy should be preceded by an in-depth analysis of the factors affecting their reliability. One of the main problems encountered in developing a strategy for improving reliability in supply chains is the limited visibility of actual demand. Since the requirements caused by the reliability condition in different parts of the supply chain differ, it is possible to solve this problem by using a hybrid strategy.

To do this, transfer the order generation point to the lowest supply chain links. In this case, we will have the following benefits:

- reduction of the number of options of the delivered products, which helps to reduce the volume of stock;

- increasing inventory management flexibility because the same components can be used in different types of finished products.

A hybrid supply chain reliability management strategy that divides the supply chain into two parts - up to the point of order, where it is advisable to use lean strategies that are characterized by standard product characteristics, long product life cycle, price and quality are selected as supplier selection criteria. After the point of order, it is useful to use strategies focused on a wide range, short product life cycle, speed, flexibility and quality as the main characteristics of supply chains.

Reliability of supply chains is ensured by a set of elements ofsupply chains ,these include: Reliability of demand forecast, reliability of planning of need for material resources, reliability of suppliers, reliability of a control system of orders and purchases, reliability of delivery, reliability of delivery, reliability of entrance control. For each reliability element, It is necessary to choose a method of ensuring reliability.

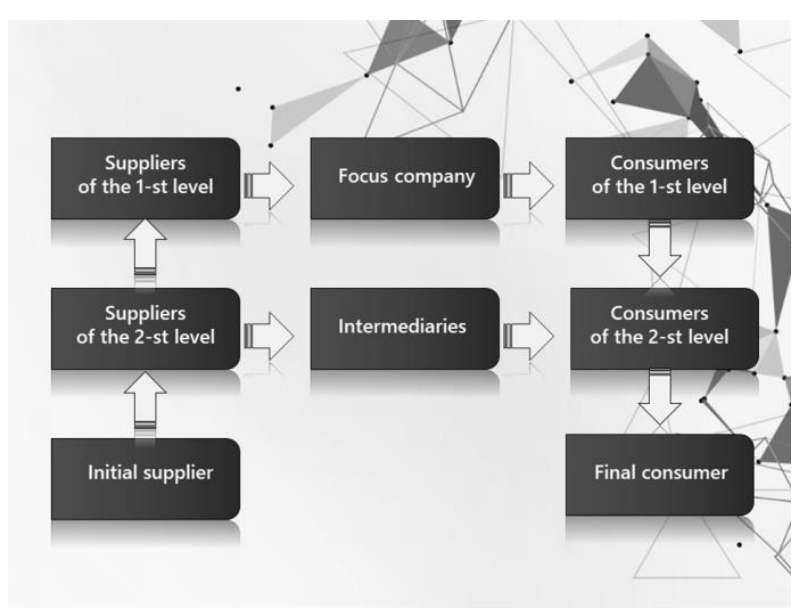

Figure 2 Supply Chain Schematic Diagram 
Table 1 Factors Influencing Supply Chain Reliability Strategy

\begin{tabular}{|l|l|l|}
\hline \multicolumn{1}{|c|}{ Factors } & Characteristics of supply chain strategies \\
\cline { 2 - 3 } & $\begin{array}{l}\text { Under conditions of relative stability } \\
\text { of the external environment }\end{array}$ & $\begin{array}{l}\text { Under conditions of high } \\
\text { uncertainty of the external } \\
\text { environment }\end{array}$ \\
\hline BasicOrientation & Performance & Efficiency \\
\hline Product characteristics & Standard & Wide Variety \\
\hline Life Cycle Products & Long & Short \\
\hline Supply chain focus & Economy on scale & Speed, flexibility and quality \\
\hline Capacity Utilization & Level is set by the production schedule & Flexibility \\
\hline Supplier selection criteria & Quality and price & $\begin{array}{l}\text { Speed, flexibility, quality. Presence } \\
\text { of reserve capacities. }\end{array}$ \\
\hline
\end{tabular}

Table 2 List of requirements ensuring the reliability of supply chains

\begin{tabular}{|l|l|}
\hline Requirements & Specification of the requirement \\
\hline Adaptability & $\begin{array}{l}\text { The SC property changes its behavior to preserve, improve, or acquire new } \\
\text { characteristics according to its intended purpose. }\end{array}$ \\
\hline Security & Resistance to a deliberate act of unlawful interference to harm \\
\hline Reliability & $\begin{array}{l}\text { The ability of the SC to operate without failure for a certain time in accordance with } \\
\text { conditions }\end{array}$ \\
\hline Recoverability & SCrecoverability \\
\hline Serviceability & SC condition, when its operation corresponds to all \\
\hline Reliability of delivery & $\begin{array}{l}\text { Combination of criteria: performance of orders, quality of services provided, product } \\
\text { range, total cost of delivery }\end{array}$ \\
\hline Margin of Safety & SC 's ability to perform its functions despite breach of contract between participants \\
\hline Response speed & $\begin{array}{l}\text { End-user service speed expressed in terms of indicators, order execution cycle time, } \\
\text { production cycle time, logistics cycle time. }\end{array}$ \\
\hline Damage & External impact causing invalid SC deviations \\
\hline Operability & Ability to perform its functions in accordance with contracts \\
\hline Failure & Self-recovering failure resulting in short-term partial loss of operability. \\
\hline Stability & $\begin{array}{l}\text { Planned mode of stable functioning of SCwhen small perturbations result in limited } \\
\text { small changes of output parameters }\end{array}$ \\
\hline
\end{tabular}

Table 3 Connection of supply chain reliability elements and supply methods.

\begin{tabular}{|c|c|}
\hline Reliability & Methods of ensuring reliability \\
\hline $\begin{array}{l}\text { Reliability of demand } \\
\text { forecasting }\end{array}$ & Selection of the most efficient method of demand forecasting \\
\hline $\begin{array}{l}\text { Reliability of Planning Material } \\
\text { Requirements }\end{array}$ & $\begin{array}{l}\text { Selection of the most efficient method of calculating requirements: Direct billing method, } \\
\text { calculation of requirements based on data on the recipe composition of the manufactured } \\
\text { products, calculation of requirements based on standard wear and tear dates, etc. }\end{array}$ \\
\hline Supplier Reliability & Selection of the most reliable suppliers based on analytical or expert methods. \\
\hline $\begin{array}{l}\text { Reliability of the Order and } \\
\text { Purchase Management System }\end{array}$ & $\begin{array}{l}\text { Reliability of the Order and Purchase Management System Selection of an appropriate } \\
\text { inventory management strategy. } \\
\text { Selection of the best type of purchase. } \\
\text { Determination of optimal delivery conditions }\end{array}$ \\
\hline Delivery reliability & Supplier reliability assessment based on KPI. \\
\hline Reliability of delivery & $\begin{array}{l}\text { Planning of optimal cargo delivery routes. Selection of the most effective method of cargo } \\
\text { safety (selection of package, transport packaging, method of loading unloading, etc.) }\end{array}$ \\
\hline Reliability of input control & $\begin{array}{l}\text { Reliability of input control Selection of the most effective method of quality and quantity } \\
\text { control }\end{array}$ \\
\hline
\end{tabular}


[2] Abramova E.R. Theoretical foundations of logistics coordination: monograph, E.R.Abaramova, M.: INFRA-M, 2017. -69c. - (Scientific thought).

[3] Bockarev A. A. Theory and methodology of process approach to modeling and integrated planning of supply chain: dis... Dr. Sciences, SPb.: SPbGIEU, 2009. $291 \mathrm{p}$.

[4] Grigoriev M. N., Dolgov A. P., Uvarov S. A. Logistics. Advanced course: training for masters. Moscow: YURITE University, 2011. 734 p.

[5] Grigoriev M. N., Uvarov S. A., Logistics. Basic course: study. Moscow: YURAIT, 2011. 782 p.

[6] Zaytsev E. I., Shurpatov I. G. Methodical approach to the development of the supply chain topology according to the criteria of reliability and minimum costs//Journal of ENGINEERING., Economics. - 2011. Edition. 2 (45), p. 229-234.

[7] Ivanov D.A. Supply Chain Management/D.A. Ivanov. SPb.: Politekhn. publishing house, 2009. 660 p.

[8] John Kotter. Matsusita's leadership. Lessons of outstanding entrepreneur of the 20th century. - M.: "Alpine Pablischer," 2011, 256 p.

[9] Litvina D.B. Terenina I.V. Peculiarities of interaction between the concept of "logistics" and "supply chain management" in construction, EngineeringNewspaper Don.2012 127p.

[10] Malevich Yu. V., Shurpatov I. G. Improving Reliability of Transport and Thermal Operations in Supply Chains, Vestn. Engineering, Economics, 2011, Issue. 1 (44), p. 175-182

[11] Michael H.Meskon, Michael Albert, Franklin Hedoury. Management bases. Williams Publishing House, 2006

[12] Mentzer, S Min,ZG Zacharia- The nature of interfirm partnering in supply chain management Journal of Retailing, 2000 - Elsevier

[13] R.K. Oliver, M.D., Weber Supply-chain management: Logistics catches up with strategy, M.L. Christopher, ed., 1982. Logistics: The strategic issues. London: Chapman and Hall., 1982. P. 63-75. 2

[14] A Otto, H Kotzab, Does supply chain management really pay? Six perspectives to measure the performance of managing a supply chain- European Journal of Operational Research, 2003, Elsevier

[15] Protsenko I. O. Logistics. Supply Chain Management: Conceptual and Strategic Aspects: Tutorial, M.: Creative Economy, 2008.
[1] Abramova E.R. Supply Chain Management: Monograph. - Moscow: «Sputnik $+\gg$ Publishing House, 2011. 253 p. 
[19] Terenina I.V. On the question of finding a compromise solution between efficiency of operation and stability of the economic system, Scientific review. 2014 No. 4-2 (23) p.127

[20] Supply Chain Management: Gower/Under Ed. J. Gatorna (Ed. R. Ogulin, M. Reynolds); Moscow: INFRA-M, 2008. 670 p.

[21] Shulzhenko T. G., Shurpatov I. G. Methods of forming a model of reliability of warehouse processes, Vestn. Engineering. Economics. - 2010. - Issue. 2 (37). p. 255-263.
[18] Terenina I.V. Peculiarities of Concept Interaction of "Logistics" and "Supply Chain Management" in Construction, Engineering Newspaper Don2015 p.32 